\title{
sciendo
}

\section{INTERNET OF THINGS AND THE ENVIRONMENT}

\section{Mirela Danubianu $^{1 *}$, Cristian Teodorescu ${ }^{2}$, Isabela Corneanu ${ }^{2}$}

Keywords: IoT, Industrie 4.0, Environmental Protection, Globalization, INNOQUA.

\begin{abstract}
Along with the well-known attributes of mankind's future (sustainable, socially inclusive, environmentally-friendly), the last few years we was witnessing the appearance of a new digital attribute. The Internet of Things (IoT) is the ongoing digital revolution that attempts to put into practice all the benefits of explosive development of digital technologies and associated communication capabilities. The huge amount of information collected by computerized planning, production management, technology risk practice and health hazards monitoring has to serve both economic development, advanced management resources, financial profit, and a better protected environment. The IoT Revolution is in its early stages and its focus is on assuring the associated infrastructure as quickly as possible (hardware, BigData software, sensor systems, protected sensitive data, safe communications). The first results are expected in optimizing and streamlining technologies in the management of non-renewable resources. It is appreciated that by 2030 , the value added by IoT will amount to about $\$ 14$ trillion in industry alone. But it would be a mistake to stop the benefits of IoT there. The authors devise a SWOT (Strength, Weakness, Opportunities and Traits) analysis, and evaluate the benefits and risks of aligning environmental/social policies to the IoT, proposing a brevity of measures to ensure that the sustainability is considered in the IoT implementation at all stages and at all levels: enterprise, industrial, geographical area, global region. The IoT vision and mission are presented in light of this approach, strategic objectives and important action directions. It also highlights the ethical issues related to the development of an interconnected world through IoT (where unrestrained access to information is stopped, who and for whose control this access has been made, etc.). The terms IoE (Internet of Environment) and IoS (Internet of Sustainability) are suggested.
\end{abstract}

\section{IoT/IoTs concept}

The Internet of Things (IoT) and the more comprehensive term Internet of Things and Services (IoTS) can be regarded as natural results of the explosive 
development of the information technology, computer networks, INTERNET communication abilities and Cloud Computing. Hardware and software in the field become global, ubiquitous, come at an increased complexity, inviting end users to take advantage of the offered capabilities in every domain of human activity. As the term INTERNET is familiar globally, only the "things" and "services" in the IoT / IoTS should be detailed. They refer not only to lifeless things but denotes devices, sensor infrastructure, experts and common people, as long as they realize their role and needed contribution, are capable of instant communication with other similar "things", without restrictions of location and/or time. Essentially, this is accomplished by interconnecting all "things" via a plethora of protocols, procedures, sets of priorities, reporting methods. Additionally, these "things" are smart, in the sense that they autonomous in taking decisions, directing actions or asking for extra involvement, in order to sort out as soon as possible, effectively and in the most efficient way any problem presented to them. The INTERNET network, the Cloud, Fog and Mobile-Computing Systems (Bonomi et al, 2012) and other similar developments ensure that at any time, the action and communication of "thing" go seamlessly and without affecting the safety of "things" and the security and integrity of data conveyed. In our paper the environment refers the universe in which IOT operates, and it includes both the natural environment and the communities, so the present work refers to all three components of sustainable development (economic, social, environmental).

The Internet of Things is always there, always dependable, recording everything, remembering all its past, never tired. The role of experts in this environment is mainly as monitors and controllers but they may also take the lead and determine required actions when an unexpected, unforeseen event happen, for which the IoT is helpless because it was not prepared, though expert systems in IoT made all efforts to find a solution.

In the vision of the European Commission, IoT and IoTS are (EU-IoT, 2009) "global, distributed networks of 'smart' objects that are capable of sensing or acting on physical systems and able to communicate with each other, other machines or computers". Smart objects are at the core of IoT / IoTS and may include all kinds of "things" described above. Most of them are already used, e.g., industrial robots, household appliances, vehicles, watches, shirts, mobile phones, tablets, computers, etc. An object becomes smart as long as its value includes:

- vast amount of data and information they can capture, store and convey,

- capacity for communication with other smart objects and with humans,

- ability of carrying our real-time control and data analysis,

- possibility to act with or without human interference,

- possibility to call for human help once their own expertise becomes useless. 
The development of IoT/IoTS was possible and took advantage of the RFID technology (Radio-Frequency Identification) but IoT/IoTS prompted also a massive progress in the field, by provoking the generation and use of more advanced systems like Bluetooth, WSN (Wireless Sensor Networks), WSAN (Wireless Sensors and Actuators Networks), etc. It can be said that currently, IoT and IoTS are capable of more than we can ask from them (with some limitations mentioned below). So, the problem is how to take advantage of these new tools, how to integrate them in the existing systems of managerial tools (Danubianu and Teodorescu, 2016).

\section{Industrie 4.0 and the environment}

At the beginning of the new millennium, it seems that humankind is facing a new Industrial revolution that includes IoT, IoTS Cyber World, Cloud computing, etc.

Translated in industrial terms, the present Revolution is known as Industrie 4.0 (I4.0, I4), a term suggested in Germany at the beginning of the XXI Century and revived after 2015 (Klitou et al, 2017). Industrie 4.0 has progressed as a wellstructured approach aiming to take advantage as soon as possible of all the advantages and opportunities present in the whole bunch of new perspectives opened by the IoT / IoTS and by software approaches like DataMining (the process of discovering various patterns in data), BigData (datasets characterized by large volumes, variety, velocity, volatility), Artificial Intelligence (AI), machine learning, expert systems, etc.

Industrie 4.0 is the industry response to the challenging offerings of IoT and its vision is for a high performance, flexible smart industry totally controlled by computers on the base of four fundamental principles:

- interoperability: equipment and humans communicate with each other via the IoT / IoTS

- information: sensor data add continuously information enabling upgrading of computer models of the real world.

- technical support for carrying out difficult tasks and solving emergencies by minimizing risks.

- real time, swift, decentralized decisions: companies become autonomous relegating to humans only conflicting situations or exceptions.

As taking advantage of all the capabilities of IoT requires extensive investment, it is natural that the implementation of the Industrie 4.0 initiative be a conjugated action of many actors. Probably the most substantiated approach is the Alliance Industrie du Futur, a tri-lateral approach by Germany, France and Italy. The status of the initiative, as of June 2017 includes (AIF, 2018): 
- a vision which is radically transforming our current economies, as innovation and digitization call for a paradigm shift in industrial production and products.

- 3 core areas of cooperation that should be replicated to all those aiming at Industrie 4.0 implementation:

a. Standardization and reference architectures for future IoT applications

b. Engagement of SMEs as test fields for the newly developed tools and procedures

c. Policy supporting group that will convey findings to EU bodies

- Skill development and qualification for operators in the new industrial environment.

A thorough analysis of the cited documents prompted an important question: Where is the environment in the Industrie 4.0 and in intended IoT / IoTS applications? Most generous intentions regard innovation, optimization, new products, better workplace, less human effort, etc. Very little - if any - regards the environment impact and protection, habitat conservation, climate change, etc. Some research directions with results already partially implemented in practice are:

- Smart homes_that include IoT management and control of buildings (heating, cooling, lighting, entertainment, security systems, household appliances);

- Smart cities where the role of IoT is to maximise the efficiency of traffic, water supply, public transport, street lighting, citizen protection (by reducing criminal activities), other city infrastructure.

- Smart Services for which IoT should be applied to public health sector, education and training, community $e$-development, participative democracy, social inclusion.

With strict reference to the industry, IoT roles are described in the subsequent section (CGI, 2018; EU-IoT, 2015).

In this context, the industry should transform organizations to become digital organizations, switch attention from product centric to customer-centric, extends digitalization beyond the enterprise. As conclusion, business priorities should be to optimize operations cost, agility and speed to market, to collaborate across the digitized value chain, to improve the customer experience, to deliver product and service with increased speed to market and last but not least to create of new revenue streams. The following outcomes are expected till 2020: IoT will connect 26 billion devices and it will generate revenues of more than Euro300 billion; 1.9 trillion in added value through sales, IoT consolidated market will grow to Euro 6.5 trillion by 2020, 5.4 billion business-to-business (B2B) connections, concentrated particularly in the industry (especially automobile) and health/fitness sectors, organisations will be $10 \%$ more profitable and $30 \%$ increased productivity by 
implementing Industrie 4.0. Unfortunately, no reference to the environment. It is treated as marginal social concern.

\section{Sustainable IoT/IoTs initiatives}

Is IoT / IoTS a good opportunity for development? The SWOT analysis presented in Table 1 tries to answer. The SWOT includes reference to the environment, wherever it is believed relevant (Greenough, 2014; AMPT, 2018).

Table 1. A brief SWOT analysis of IoT/IoTS initiatives

\begin{tabular}{|c|c|}
\hline Strengths & Weaknesses \\
\hline $\begin{array}{l}\text { - INTERNET becomes a way of life via social } \\
\text { networks and communication capabilities } \\
\text { - INTERNET networks exist all over the } \\
\text { world as it is not linked with level of industrial } \\
\text { development, level of training, etc. } \\
\text { - Companies already extensively use } \\
\text { computing and computer networks so } \\
\text { employees are more or less familiar with the } \\
\text { field } \\
\text { - } 1.6 \mathrm{Gt} \text { of } \mathrm{CO}_{2} \text { emissions reduced in the } \\
\text { agricultural sector by } 2020 \\
\text { - By } 2020 \text { : over } 2.0 \mathrm{Gt} \text { of } \mathrm{CO}_{2} \text { emissions } \\
\text { reduced in the energy sector production sector } \\
\text { by } 2020 \text { and } 1.9 \mathrm{Gt} \mathrm{CO}_{2} \text { emissions reduced } \\
\text { during the next } 5 \text { years by improving power } \\
\text { transport networks (result conflicting with the } \\
\text { following mention). } \\
\text { - } 23.3 \text { billion IoT devices connected by } 2019 \\
\text { across all sectors of which } 9.1 \text { billion devices in } \\
\text { the enterprise IoT (compare to } 9 \text { billion mobile } \\
\text { phone and tablet market in } 2019 \text { ) }\end{array}$ & $\begin{array}{l}\text { - Digitization requires huge investment in } \\
\text { hardware and software } \\
\text { - Full capability of IoT is attained if the } \\
\text { Company is part of a chain that already } \\
\text { understands and implements digitization. } \\
\text { Otherwise, the value chain will move with the } \\
\text { speed of the least efficient member. } \\
\text { - Digitization must go beyond Company } \\
\text { fences (additional investment!) } \\
\text { - Trained experts needed to operate IoT } \\
\text { networks and Industrie 4.0 architecture } \\
\text { developments } \\
\text { - Massive, accelerated consumption of power } \\
\text { by the newly commissioned IoT networks } \\
\text { - Increased (in absolute values) environmental } \\
\text { impact of the power sector due to larger } \\
\text { demand for the IoT sector } \\
\text { - } 53 \text { Mt of e-waste disposed worldwide in } \\
2013 \text { (hardware that was not-IoT-ready) }\end{array}$ \\
\hline Opportunities & Threats \\
\hline $\begin{array}{l}\text { - Companies and public entities that already } \\
\text { use the smart object paradigm experienced } \\
\text { important advantages over the competitors. } \\
\text { E.g., } 527 \text { Smart Energy Grid Projects in EU } \\
\text { only (JRC, 2018); Smart Cities in EU are also } \\
\text { progressing rapidly (Smart Cities EU, 2018). } \\
\text { - Starting earlier the IoT implementation and } \\
\text { the Industrie } 4.0 \text { paradigm gives company extra } \\
\text { edge over similar entities and define trends for } \\
\text { future development (e.g., the self-driving } \\
\text { electric car; BMW, 2018) } \\
\text { - \$255 billion spending on enterprise IoT by } \\
2019 \text { (2014: } \$ 46.2 \text { billion) }\end{array}$ & $\begin{array}{l}\text { - Implementation of IoT, IoTS is hindered by } \\
\text { major dysfunctionalities not yet sorted out by } \\
\text { the IT industry (standards for collecting, } \\
\text { storage and conveying data, compatibility of } \\
\text { various software products, etc. } \\
\text { - confidentiality of data stored in cloud or } \\
\text { other networks is not assured! } \\
\text { - Security of information storage is also a } \\
\text { major issue: hackers could access databases and } \\
\text { destroy them if a ransom is not paid. } \\
\text { - Sustainability is not explicitly a part of the } \\
\text { IoT philosophy } \\
\text { - } 75 \% \text { of enterprise projects in IoT stuck } \\
\text { because of the absence of network } \\
\text { hardware/software (security problems, } \\
\text { compatible data protocols, etc.). }\end{array}$ \\
\hline
\end{tabular}


The problem with the environment and social sector, as would-be components of the IoT is that they are neither networks that can be turned on and off using a switch nor a "thing" that can become smart via proper programming in the way a robot can be.

Table 2. Ensuring the sustainability of IoT / IoTS

\begin{tabular}{|c|c|c|}
\hline Business components & Environmental components & Social initiatives \\
\hline $\begin{array}{l}\text { Design, generate solutions, } \\
\text { compare scenarios }\end{array}$ & $\begin{array}{l}\text { Life Cycle Analysis in all stages } \\
\text { of business development (ISO } \\
14040 \text { ) }\end{array}$ & $\begin{array}{l}\text { Engage/inform all stakeholders } \\
\text { about your business } \\
\text { development }\end{array}$ \\
\hline $\begin{array}{l}\text { Digitized technology lines; } \\
\text { planning, asset management } \\
\text { Optimization } \\
\text { Quality management (ISO } \\
9000 \text { ) }\end{array}$ & $\begin{array}{l}\text { Sustainable Land use, sustainable } \\
\text { buildings } \\
\text { Best available technologies } \\
\text { Include the environmental } \\
\text { restrictions in the Optimization } \\
\text { criteria - } \\
\text { ISO } 14000\end{array}$ & $\begin{array}{l}\text { Work together with } \\
\text { communities in devising and } \\
\text { evaluating technology impact } \\
\text { Include the social dimension in } \\
\text { the Optimization criteria } \\
\text { Safer workplaces, } \\
\text { ISO } 18000\end{array}$ \\
\hline $\begin{array}{l}\text { Raw materials, utilities, } \\
\text { energy sources } \\
\text { Preventive maintenance } \\
\text { Logistics }\end{array}$ & $\begin{array}{l}\text { Industrial symbiosis, Circular } \\
\text { Economy (Circular Economy, } \\
2018 \text { ). } \\
\text { ISO 14051 }\end{array}$ & Rely on local specialists \\
\hline $\begin{array}{l}\text { Communication } \\
\text { infrastructure, real-time } \\
\text { control capabilities, on-line } \\
\text { decision making, integrated } \\
\text { networks, protocols (in- } \\
\text { house and over the entire } \\
\text { supply chain (sensors, } \\
\text { programs, BigData) }\end{array}$ & $\begin{array}{l}\text { Include all info related to } \\
\text { environment }\end{array}$ & $\begin{array}{l}\text { Make available as much info as } \\
\text { possible to all stakeholders }\end{array}$ \\
\hline $\begin{array}{l}\text { Customer Satisfaction } \\
\text { Management }\end{array}$ & $\begin{array}{l}\text { Ensure the habitat is full protected } \\
\text { and thriving }\end{array}$ & $\begin{array}{l}\text { Feedback from communities, } \\
\text { stakeholders }\end{array}$ \\
\hline Product delivery, service & Life-Cycle Analysis & Honest marketing \\
\hline $\begin{array}{l}\text { Human Capital \& } \\
\text { Resources, Employee } \\
\text { Satisfaction Management }\end{array}$ & $\begin{array}{l}\text { Develop employee awareness } \\
\text { encourage environment initiatives }\end{array}$ & $\begin{array}{l}\text { Collaborate with schools, } \\
\text { academia for substantial } \\
\text { training in sustainability }\end{array}$ \\
\hline $\begin{array}{l}\text { Cooperation along all the } \\
\text { supply chain }\end{array}$ & $\begin{array}{l}\text { Ensure strictest environmental } \\
\text { regulations are observed by all } \\
\text { your business partners }\end{array}$ & $\begin{array}{l}\text { Ensure Corporate Social } \\
\text { Responsibility (ISO 26000) is } \\
\text { observed by all your business } \\
\text { partners (Werther and } \\
\text { Chandler, 2006) }\end{array}$ \\
\hline Openness and transparency, & $\begin{array}{l}\text { Responsible Care (RC, 2018) } \\
\text { Become part of environmental } \\
\text { projects }\end{array}$ & Responsible Care (RC, 2018) \\
\hline
\end{tabular}

Table 2 illustrates the main components of a modern business company that could be elements of the IoT/IoTS. Adjacently, elements of environmental and 
social concern are mentioned, elements that, once inserted in the mainframe of the IoT/IoTS would turn them into a sustainable endeavour, following the paradigm of the 3 pillars of sustainability (economic, environmental, social).

Difficulties in inserting social and environmental elements in the IoT approach comes from:

a. Large time-lags in communication with communities or environmental enforcement institutions, NGOs, when compared with the communications among smart objects. The solution could be the set up of an Advising Board that could take decision on the spot, whenever need be. The Advisory Board could include representatives of the Company implementing IoT, of communities, Environmental Protection Agencies, NGOs, etc. Internet communications could hasten up the multi-criteria decision-making process;

b. Optimization criteria, so simple when they are limited to the performances of the production line, suppliers and customers, become extremely complicated when they must include environmental and social concern. A first step could be devising Pareto frontiers for the feasibility domain of the technical solutions, keeping in mind environmental and social restrictions (Agrawal et al, 2004). Illustrations of modified optimization criteria are available (Hoffenson et al, 2013). The international scientific community is aware of the subject and the series of Global Conferences of Sustainable Manufacturing (GCSM, 2018) constitutes the best proof for this assertion.

c. The unpredictable character of the environment, especially in the present climate change trend complicates further the set up of a sustainable IoT. This could still be achieved only by permanent international co-operation and by creating an Internet of the Environment (IoE) as a part of IoT / IoTS. It could include global networks of climate sensors, large data storage and processing facilities, communicating procedures with all stakeholders, protocols for emergency actions. In these conditions the IoS (Internet of Sustainability) could replace IoT and IoTS. This would give the IoT the full character of awareness and preventive action that is directed to the health of our planet and to the thriving of human civilization.

d. At the political level, adding sustainability dimensions to IoT should lead to decoupling growth from development and resource use, to systematic dissemination of good practices in the field, to various measures to encourage such developments.

\section{The romanian experience}

A number of initiatives in the field of power smart grids, smart cities, etc., are active in Romania. The subsequent paragraphs details projects related to the Circular Economy and Industrial Symbiosis (replicable in all organizations) or to 
the environment. The Projects have been awarded international financing and implemented in the NE- part of Romania:

- The ECOREG Project, was the first of its kind in this part of the world and was directed to the understanding and implementation of the Circular Economy (industrial symbiosis). The pilot project was implemented between 2009 and 2011 in Suceava County with an overall budget of 880,000 EUR. 200 companies were involved, resulting in 114 partners hills (synergies) including 13 categories of waste, recycling more than 550,000 tons of waste, reducing the $\mathrm{CO}_{2}$ emissions by some 130,000 tons, following the replacement of virgin materials with alternative resources (ECOREG, 2018).

- The Norwegian - financed PAZEWAIA Project - Partnerships for ZeroWaste Industrial Activities, (PAZEWAIA 2018). The Project started the Inventory of wastes and any other resources available in the Focal Zone, elements that can be reinserted in the economic cycle. The Project training dimensions focused upon Cleaner Production and Material and Energy Flow Accounting, generating, together with local managers, options for reducing the amount of waste that should be cared for. Symbiotic business partnerships in the Focal Zone were established (Norwegian Business partnerships with Romanian Companies, very encouraged), for adding value to available resources (wastes, production capacities, laboratories, experts, transport facilities, training capabilities, workshops not used, etc.) and for reducing the need of virgin resources, fossil fuels and the environmental footprint of economic activities in the Focal Area (5 counties in the NE part of Romania).

- The current INNOQUA Project (INNOQUA 2018), is a Horizon 2020 EUfunded project involving $20+$ partners that seeks to demonstrate in real conditions a modular system for water treatment based on the purifying capacity of biological microorganisms (earthworms, zooplankton and microalgae). The technical solution is especially developed for rural areas where there are no sewage and water treatment systems available. In the Suceava County, the INNOQUA Partner is the RIITMIC COM Company, a SME that will be used to illustrate the potentiality of IoT. The Company have several lines of business (selling car fuel, firewood, collecting waste from adjacent communes, turning sawdust into briquettes, valueing local agricultural resources). The INNOQUA will offer the wastewater treatment capabilities. The computer programs currently under development try to simulate the operations of all business lines, integrate all of them and optimize their role and functions, keeping in mind the environment (limiting water consumption and pollutant emissions) and social aspects (contributing to the development of local communities, better and safer workplace, using local workforce). The RITMIC Company will become a pilot, demonstrative Project for the IoT trends under way. 


\section{Conclusions}

A critical analysis of the new trends in business activities was performed and the various aspects of IoT / IoTS were evaluated. For the case of the manufacturing industry, the Industrie 4.0 initiative prove a factor of immense pressure on all business companies to adopt IoT and IoTS as soon as possible, in order to keep pace with their challenging competitors. In the process, there is little time for environmental or social concern, making the IoT evaluate far away from the 3 pillars of sustainable development. The paper tries to point out where the IoT could be amended and by what kind of actions, in order to take into consideration, the environment, the social world and the interests of all stakeholders.

Apart of the problems connected to the safety of data storage and conveying, such developments of IoT complicates considerably the mathematical aspects of optimization. However, initiatives in the field does exist and should be encouraged at the policy level in each country, by relevant instruments as subsidies or other financial or other incentives (better access to funds, covering training courses for personnel, free dissemination activities, etc.).

The terms IoE (Internet of Environment) and IoS (Internet of sustainability) are suggested.

\section{References}

Agrawal, G. et al (2004), Intuitive Visualization of Pareto Frontier for Multi-Objective Optimization in n-Dimensional Performance Space, American Institute of Aeronautics and Astronautics, available at: https://arc.aiaa.org/doi/abs/10.2514/6.2004-4434 retrieved May 2, 2018.

AIF (2018), Alliance Industrie du Futur: Shared Action Plan - Germany, France, Italy, Industrie $\quad 4.0 \quad$ Platform https://www.plattformi40.de/I40/Redaktion/EN/Downloads/Publikation/shared-actionplan-fr-de-it.html accessed May 2, 2018.
AMPT (2018),
The
Environmental
impact
of $\quad I o T$, http://www.advancedmp.com/environmental-impact-of-iot/ accessed May 14, 2018.

BMW (2018), BMW unveils its vision for a self-driving electric car for 2021 https://edition.cnn.com/2018/09/27/cars/bmw-vision-inext-self-drivingelectric/index.html accessed May 2, 2018.

Bonomi, F. et al (2012), Fog Computing and Its Role in the Internet of Things, https://dl.acm.org/citation.cfm?id=2342513, accessed April 2, 2018.

Buyya, R. and Dasterdji, A.V. (Editors) (2016), Internet of Things - Principles and Paradigms, Department of Computing and Information Systems - The University of Melbourne, Australia, Elsevier.

CGI (2018) Industry 4.0 - Making your business more competitive, https://www.cgi.com/en/overview accessed April 11, 2018. 
Circular Economy (2018), http://ec.europa.eu/environment/circulareconomy/index_en.htm accessed May 2, 2018.

Danubianu, M. and Teodorescu C. (2016), Managerial Tools and Sustainable Development, PESD 10(1), 2016, pp 151-160.

ECOREG (2009), http://ec.europa.eu/environment/enveco/resource_efficiency /pdf/business/RE_in_Business_M1_IndustrialSymbiosis.pdf accessed May 12, 2018.

EU-IoT (2009), Internet of Things: An Action Plan For Europe COM/2009/0278 final, https://eur-lex.europa.eu/legal-content/EN/TXT/?uri=COM:2009:0278:FIN accessed April 19, 2018.

EU-IoT (2015), The Internet of Things, Opportunities and challenges, available at http://www.europarl.europa.eu/RegData/etudes/BRIE/2015/557012/EPRS_BRI(2015) 557012 EN.pdf accessed May 2, 2018.

GCSM (2018), Global Conferences on Sustainable Manufacturing, https://gcsm.eu/ accessed Aug 22, 2018.

Greenough, J. (2014) Business Insider https://www.businessinsider.com/the-enterpriseinternet-of-things-market-2014-12 accessed Sep 14, 2018

Hoffenson, S. et al (2013), A Multi-objective Tolerance Optimization Approach for Economic, Ecological, and Social Sustainability, 20th CIRP International Conference on Life Cycle Engineering, Singapore, 2013.

INNOQUA (2018), https://innoqua-project.eu/ accessed May 12, 2018.

JRC (2018), Smart Grid Projects in EU, https://ses.jrc.ec.europa.eu/inventory accessed May 2, 2018.

Klitou, D. et al (2017), Germany: Industrie 4.0, Report prepared for the European Commission, the Digital Transformation Monitor Platform, retrieved on April 12, 2018 from the site https:/ec.europa.eu/growth/toolsdatabases/dem/monitor/sites/default/files/DTM_Industrie\%204.0.pdf . Additional information at: https://ec.europa.eu/growth/tools-databases/dem/monitor/

PAZEWAIA (2018), http://www.id-norway.com/projects/partnerships-for-zero-wasteindustrial-activities-pazewaia/ accessed May 12, 2018.

RC (2018), Responsible Care - see the RC Portal at http://raining.itcilo.it/actrav_cdrom1/english/global/code/responsi.htm , accessed April 24, 2018.

Smart Cities EU (2018), http://www.smart-cities.eu/?cid=01\&ver=4 accessed May 2, 2018

WEF (2018), The Next Economic Growth Engine, World Economic Forum White Paper, http://www3.weforum.org/docs/WEF_Technology_and_Innovation_The_Next_Econo mic_Growth_Engine.pdf accessed Sep 14, 2018.

Werther, W.B. Jr. and Chandler, D. (2006), Strategic Corporate Social Responsibility, Thousand Oaks, California, United States. 